\title{
沉积温度对等离子增强化学气相沉积法制备的 $\operatorname{SiN}_{\mathrm{x}}: \mathrm{H}$ 薄膜特性的影响
}

\author{
闻震利曹晓宁周春兰赵 雷 李海玲 王文静 \\ (中国科学院电工研究所, 太阳能热利用及光伏系统重点实验室, 北京 100190)
}

\begin{abstract}
摘要：利用 Centrotherm 公司生产的管式等离子增强化学气相沉积(PECVD)设备在 $p$ 型抛光硅片表面沉积 $\mathrm{SiN}_{x}: \mathrm{H}$ 薄膜, 研究沉积温度对 $\mathrm{SiN}_{\mathrm{x}}: \mathrm{H}$ 薄膜的组成及光学特性、结构及表面钝化特性的影响. 然后采用工业化的 单晶硅太阳电池制作设备和工艺制作太阳电池, 研究不同温度制备的薄膜对电池电性能的影响. 测试结果表 明: $\mathrm{SiN}_{\mathrm{x}}$ : $\mathrm{H}$ 薄膜的折射率随着沉积温度的升高而变大, 分布在1.926-2.231之间, 这表明 $\mathrm{Si} / \mathrm{N}$ 摩尔比随着沉积 温度的增加而增加; 当沉积温度增加时, 薄膜中 $\mathrm{Si}-\mathrm{H}$ 键和 $\mathrm{N}-\mathrm{H}$ 键浓度呈现减小趋势, 而 $\mathrm{Si}-\mathrm{N}$ 键浓度逐渐升 高, 薄膜致密度增加; 随着沉积温度的升高, $\mathrm{SiN}_{\mathrm{x}}$ : $\mathrm{H}$ 薄膜中的氢析出导致了钝化硅片的有效少子寿命先升高后 降低, 并且有效少子寿命出现明显的时间衰减特性. 当沉积温度为 $450^{\circ} \mathrm{C}$ 时, 薄膜具有最优的减反射和表面钝 化效果. 采用不同温度PECVD制备的 5 组电池的电性能测试结果也验证了这一结果.
\end{abstract}

关键词: $\mathrm{SiN}_{x}: \mathrm{H}$ 薄膜; 沉积温度; 结构特性; 钝化; 太阳电池; 效率 中图分类号： O644; TM914

\section{Influence of Deposition Temperature on the SiN :H Film Prepared by Plasma Enhanced Chemical Vapor Deposition}

\author{
WEN Zhen-Li \\ CAO Xiao-Ning \\ ZHOU Chun-Lan \\ ZHAO Lei \\ LI Hai-Ling WANG Wen-Jing*
}

(Key Laboratory Solar Thermal Energy and Photovoltaic Systems, Institute of Electrical Engineering, Chinese Academy of Sciences, Beijing 100190, P. R. China)

\begin{abstract}
Hydrogenated silicon nitride films were prepared on the $p$-type polished silicon substrates by the direct plasma enhanced chemical vapor deposition (PECVD). The influences of deposition temperature on the composition, optical characteristics, structural characteristics, and passivation characteristics of the $\mathrm{SiN}_{x}: \mathrm{H}$ film were studied. All the solar cell devices were fabricated using industrial state-of-art crystal silicon solar cell technology. The influence of deposition temperature on the as-fabricated cell's electrical performance is demonstrated. The refractive index of the film ranges from 1.926 to 2.231 and it increases with an increase in the deposition temperature. This shows that the $\mathrm{Si} / \mathrm{N}$ mole ratio also increases with deposition temperature. The $\mathrm{Si}-\mathrm{H}$ bond and the $\mathrm{N}-\mathrm{H}$ bond break and form a new $\mathrm{Si}-\mathrm{N}$ bond when the deposition temperature is higher. This increase in the $\mathrm{Si}-\mathrm{N}$ concentration results in an increase in film density. The effective minor carrier lifetime of the coated wafer increases initially with the substrate temperature. At a temperature of $450{ }^{\circ} \mathrm{C}$ the effective minor carrier lifetime begins to decrease. This phenomenon can be explained by $\mathrm{H}$ extraction from the film. For all the samples, the effective minor carrier lifetime degrades with time. The $\mathrm{SiN}_{\mathrm{x}}: \mathrm{H}$ film prepared at a deposition temperature of $450{ }^{\circ} \mathrm{C}$ shows the best
\end{abstract}

Received: January 18, 2011; Revised: March 26, 2011; Published on Web: May 10, 2011.

"Corresponding author. Email: wangwj@mail.iee.ac.cn; Tel: +86-10-82547042.

The project was supported by the National High-Tech Research and Development Program of China (863) (2007AA052437) and Main Direction of Knowledge Innovation Program of the Chinese Academy of Sciences (KGCX2-YW-382).

国家高技术研究发展计划(2007AA052437)和中国科学院知识创新工程重要方向项目(KGCX2-YW-382)资助

(C) Editorial office of Acta Physico-Chimica Sinica 
anti-reflection and surface passivation properties. The electrical performance of the fully functional solar cells is also demonstrated and the optimized results are highlighted and discussed.

Key Words: $\mathrm{SiN}_{\mathrm{x}}: \mathrm{H}$ thin film; Deposition temperature; Structural property; Passivation; Solar cell; Efficiency

\section{1 引言}

晶体硅太阳电池的表面积与体积的比率大, 表 面复合严重. 此外, 与电子级硅片相比, 太阳能级单 晶体硅和多晶体硅体内存在大量的杂质和缺陷, 而 这些杂质和缺陷会充当复合中心, 增加复合速率. ${ }^{1,2}$ 表面复合和杂质缺陷复合会显著降低少子寿命, 降 低电池的短路电流和开路电压, 进而影响电池的转 换效率. 因此减少表面复合和杂质复合是进一步提 高晶体硅电池效率的关键. ${ }^{3}$ 目前产业化生产的晶体 硅太阳电池全部采用增强的等离子化学气相沉积 (PECVD)工艺制备 $\mathrm{SiN}_{x}: \mathrm{H}$ 薄膜对硅片表面进行钝 化, 减少表面复合和杂质复合; 这层薄膜同时还具 有光学减反射的作用. PECVD法制备薄膜的优点 有: (1) 沉积温度低 $\left(<500^{\circ} \mathrm{C}\right)$, 硅中少子寿命影响较 小, 而且生产能耗低; (2) 沉积速度较快, 产能大, 工 艺重复性好; (3) $\mathrm{SiN}_{x}: \mathrm{H}$ 薄膜的折射率分布在 1.8-2.3之间, 与硅的折射率相匹配, 可以获得完美 的减反射效果; (4) 薄膜氢含量高, 具有优良的表面 钝化和体钝化效果: 薄膜中的固定正电荷能够对硅 片表面起到场效应钝化效果, 可以有效地降低表面 复合, 提高电池效率; 薄膜中的 $\mathrm{H}$ 还会向硅片体内扩 散进行体钝化, 特别是对多晶体硅太阳电池的转换 效率有很好的改善. ${ }^{3}$

$\mathrm{SiN}_{x}: \mathrm{H}$ 薄膜的物理、化学及钝化特性取决于制 备方法和工艺参数, 在过去的几十年里, 研究人员进 行了大量关于工艺参数对薄膜特性影响的实验研 究, ${ }^{4-7}$ 得出了很多被广泛认同的一致规律, 用于指导 产业化生产中 $\mathrm{SiN}_{x}: \mathrm{H}$ 薄膜沉积工艺; 然而在之前的 实验研究中, $\mathrm{SiN}_{x}: \mathrm{H}$ 薄膜大部分都是使用用于实验 研究的小型PECVD 设备制备的, 因此实验结论对 产业化生产的指导意义不大. 而且这些研究都是针 对 $\mathrm{NH}_{3}$ 和 $\mathrm{SiH}_{4}$ 流量比、功率、腔体压强这三个参数对 薄膜性质的影响进行的. 虽然也有人观察到了沉积 温度对薄膜性质的影响. ${ }^{8}$ 但也局限于给出了沉积速 率、折射率、钝化特性的实验结果, 并没有给出沉积 温度影响这些特性的机理.

本文重点研究产业化中大量应用的直接
PECVD法制备 $\mathrm{SiN}_{x}: \mathrm{H}$ 薄膜工艺, 沉积温度对薄膜组 成/减反射特性、结构特性/针化特性的影响和机理. 同时对 $\mathrm{SiN}_{x}: \mathrm{H}$ 薄膜表面钝化效果的衰退现象进行 了观察研究. 最后根据这些实验结果, 研究不同沉积 温度条件制备的 $\mathrm{SiN}_{x}: \mathrm{H}$ 薄膜对太阳电池性能的影 响.

\section{2 实 验}

使用直接法低频 $(40 \mathrm{kHz})$ 管式 PECVD 设备 (Centrotherm 公司)制备 $\mathrm{SiN}_{x}: \mathrm{H}$ 薄膜. 使用的工艺气 体是 $\mathrm{SiH}_{4}$ (纯度: $99.995 \%$ ) 和 $\mathrm{NH}_{3}$ (纯度: $99.998 \%$ ). 祄底电阻率为 $1 \Omega \cdot \mathrm{cm}$ 的单面抛光的 $p$ 型 Czoehralski 法 $(\mathrm{CZ})$ 直拉单晶硅片, 大小为 $125 \mathrm{~mm} \times 125 \mathrm{~mm}$. 在 沉积 $\mathrm{SiN}_{x}$ 薄膜之前用标准的 RCA 清洗工艺清洗硅 片, 在进入反应腔体之前用 $\mathrm{HF}$ 和 $\mathrm{HCl}(\mathrm{HF}: 3 \%, \mathrm{HCl}$ : 7\%)的混合溶液清洗硅片, 去掉硅片表面的氧化层 和金属离子. 在硅片抛光表面沉积氮化硅, 沉积温度 的变化范围是 $400-500{ }^{\circ} \mathrm{C}$, 而其它的沉积参数 $\left(\mathrm{NH}_{3}\right.$ 和 $\mathrm{SiH}_{4}$ 流量比 42:5、功率 $810 \mathrm{~W}$ 、腔体压强 226.674 $\mathrm{Pa}$ )保持不变. 每一组温度实验的样品数为 10 片左右.

PECVD 沉积 $\mathrm{SiN}_{x}: \mathrm{H}$ 薄膜一般是由 $\mathrm{SiH}_{4}$ 和 $\mathrm{NH}_{3}$ 在等离子体气氛下反应生成, 反应式如下:

$$
\mathrm{SiH}_{4}+\mathrm{NH}_{3} \rightarrow \mathrm{SiNH}+3 \mathrm{H}_{2}
$$

在低压下, 令射频发生器产生高频电场, 使电极间的 气体发生辉光放电, 产生非平衡等离子体. 这时反应 气体的分子、原子和离子均处于环境温度, 而电子却 被电场加速, 获得很高的能量将反应的气体分子激 活, 使原本高温下才发生的反应在低温时就能发生.

利用椭偏仪(波长 $633 \mathrm{~nm}$, 法国 SOFRA 公司, 型 号: SOPRA-GEs)测量 $\mathrm{SiN}_{x}: \mathrm{H}$ 薄膜的折射率和厚度; 采用傅里叶变换红外(FTIR)透射谱研究薄膜中氢含 量和 $\mathrm{Si}-\mathrm{H} 、 \mathrm{~N}-\mathrm{H}$ 和 $\mathrm{Si}-\mathrm{N}$ 键的密度, 所用仪器为 美国 Agilent 公司生产, 型号为 Varian Excalibur 3100 ; 使用微波光电导衰退法(MWPCD)测量有效少 子寿命 $\left(\tau_{\text {eff }}\right.$, 所用仪器为匈牙利 Semilab 公司生产, 型号为WT-2000. 最后在电池制作过程中选用 200 $\mu \mathrm{m}$ 厚的硅片, 采用标准的单晶硅太阳电池制造工 
艺: 制线、扩散制结、等离子体去边、去磷硅玻璃、沉 积 $\mathrm{SiN}_{x}: \mathrm{H}$ 薄膜、表面金属化, 制备 5 组单晶硅太阳电 池, 每组电池代表了不同的 PECVD沉积温度, 然后 测试太阳电池的性能参数, 进行比较分析.

\section{3 结果和讨论}

\section{1 薄膜组成特性和光学折射率}

在用直接 PECVD 法生长氮化硅时, 那些具有 化学反应活性的原子、分子、基团是在电极间的射频 电场中被电离的. 这些具有反应活性的粒子将会在 硅片表面反应生成 $\mathrm{SiN}_{x}: \mathrm{H}$ 薄膜. 相对于高能的等离 子体, 沉积温度的升高对到达硅片表面的活性粒子 数量的影响非常有限, 因此对沉积速率的影响很小. 表 1 给出了不同沉积温度条件下制备的 $\mathrm{SiN}_{x}: \mathrm{H}$ 薄膜 的厚度、沉积速率和折射率的变化. 沉积速率是由薄 膜厚度除以沉积时间得到的. 从表 1 中可以看出, 虽 然沉积速率有变大的趋势, 但变化很小.

但是随着沉积温度升高, 祄底硅片的温度也在 升高, 这使吸附到硅片表面的活性原子、分子、基团 的能量增加, 并使这些活性粒子在基片表面的扩散、 迁移能力增强. 这样随着温度的升高虽然不能增加 到达硅片的活性粒子的数量, 但是会使这些粒子反 应更加充分. 由于 $\mathrm{Si}-\mathrm{H}$ 键较 $\mathrm{N}-\mathrm{H}$ 键具有更小的 激活能, 所以温度的升高会使参与反应的含有 $\mathrm{Si}-$ $\mathrm{H}$ 键的活性粒子较含有 $\mathrm{N}-\mathrm{H}$ 键的活性粒子多, 这 就会增加薄膜的 $\mathrm{Si} / \mathrm{N}$ 摩尔比(下同). $\mathrm{SiN}_{x}: \mathrm{H}$ 薄膜的 折射率与薄膜中 $\mathrm{Si} / \mathrm{N}$ 比密切相关. 不同的研究人 员分别给出了使用不同的设备制备的 $\mathrm{SiN}_{x}: \mathrm{H}$ 薄膜 的折射率与 $\mathrm{Si} / \mathrm{N}$ 比的近似经验公式, 910 其中
表 1 不同温度沉积的 $\mathrm{SiN}_{x}: \mathrm{H}$ 薄膜的厚度 $(d)$, 沉积速率 $(v)$ 和折射率 $(n)$

Table $1 \mathrm{SiN}_{x}: \mathrm{H}$ thickness $(d)$, deposition velocitys (v), and refractive index $(n)$ at different deposition temperatures

\begin{tabular}{ccccc}
\hline No. & $T /{ }^{\circ} \mathrm{C}$ & $d / \mathrm{nm}$ & $v /\left(\mathrm{nm} \cdot \mathrm{min}^{-1}\right)$ & $n$ \\
\hline 1 & 400 & 120.9 & 7.9 & 1.926 \\
2 & 425 & 117.9 & 7.7 & 2.052 \\
3 & 450 & 133.1 & 8.7 & 2.095 \\
4 & 475 & 130.7 & 8.5 & 2.137 \\
5 & 500 & 133.2 & 8.7 & 2.231 \\
\hline
\end{tabular}

Bustarret 给出的折射率 $(n)$ 和 $\mathrm{Si} / \mathrm{N}$ 比近似公式适用 于 Centrotherm PECVD 制备的 $\mathrm{SiN}_{x}: \mathrm{H}$ 薄膜: ${ }^{10,11}$

$$
n=1.22+0.61 x
$$

式中 $x$ 为 $\mathrm{Si} / \mathrm{N}$ 摩尔比.

由表 1 的实验结果可知, 随着沉积温度的升高, 薄膜的折射率也在升高, 并且处于 1.926-2.231之 间. 根据近似公式(2)可以计算得出的 $\mathrm{SiN}_{x}: \mathrm{H}$ 薄膜的 $\mathrm{Si} / \mathrm{N}$ 摩尔比从 1.16 提高到 1.66 .

对于硅太阳电池, 根据薄膜光学原理, 满足在 $600 \mathrm{~nm}$ 波长处最低反射率的薄膜的折射率应该选 择为硅材料和空气折射率的几何平均值, 即在 2.0 左 右. 根据表 1 可知, 沉积温度在 400-450 ${ }^{\circ} \mathrm{C}$ 之间, $\mathrm{SiN}_{x}$ : $\mathrm{H}$ 薄膜减反射效果最优. 确定了薄膜折射率后, 可以通过控制沉积的时间来控制薄膜的厚度, 从而 达到最佳的减反效果.

\section{2 薄膜结构特性和钝化特性}

很多实验研究表明 $\mathrm{SiN}_{x}: \mathrm{H}$ 薄膜的氢含量和致 密度对薄膜的表面钝化效果和体钝化效果都至关重 要. 图 1 为在不同沉积温度下制备的 $\mathrm{SiN}_{x}: \mathrm{H}$ 薄膜的 傅里叶变换红外透射谱. 图 1 中的各个吸收峰根据 薄膜的厚度进行了归一化处理, 并且为了便于比较,

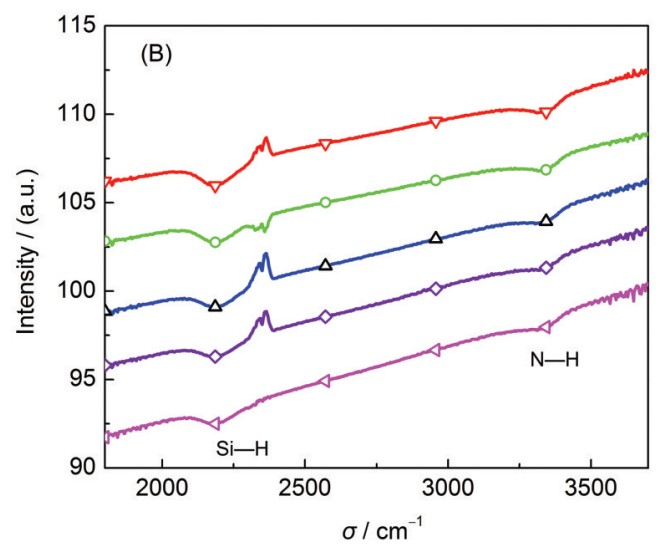

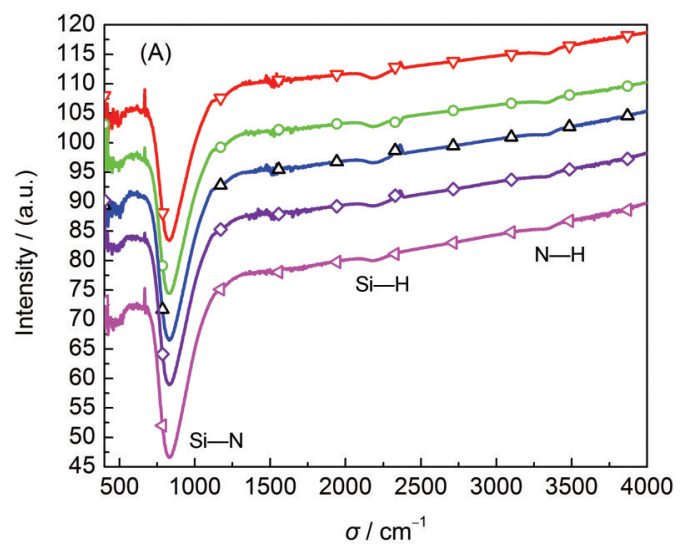

图 1 不同沉积温度下制备的 $\mathrm{SiN}_{x}: \mathrm{H}$ 薄膜的傅里叶变换红外透射谱

Fig.1 The Fourier transform infrared transmission spectra with different deposition temperatures

(A) spectra of $\mathrm{Si}-\mathrm{N}$ bond, $\mathrm{Si}-\mathrm{H}$ bond, $\mathrm{N}-\mathrm{H}$ bond; (B) enlarged spectra of $\mathrm{Si}-\mathrm{H}$ bond, $\mathrm{N}-\mathrm{H}$ bond $T /{ }^{\circ} \mathrm{C}: \neg-400, \multimap 425, \neg 4450, \leadsto 475, \smile 500$ 
在纵轴上人为地上下错开. $850 \mathrm{~cm}^{-1}$ 附近的峰对应 着 $\mathrm{Si}-\mathrm{N}$ 键伸缩模式, 在 $1200 \mathrm{~cm}^{-1}$ 附近为弯曲模 式, 在 3360-3460 $\mathrm{cm}^{-1}$ 为 $\mathrm{N}-\mathrm{H}$ 键的伸缩模式, 2170 $\mathrm{cm}^{-1}$ 分别对应着 $\mathrm{Si}-\mathrm{H}$ 键摇摆模式和伸缩模式. ${ }^{2}$

从图 1 我们可以看到, 随着沉积温度升高, $\mathrm{SiN}_{x}$ : $\mathrm{H}$ 薄膜中 $\mathrm{Si}-\mathrm{N}$ 键吸收峰强度增强, 而 $\mathrm{Si}-\mathrm{H}$ 键和 $\mathrm{N}-\mathrm{H}$ 键吸收峰强度减弱. 在分析 $\mathrm{SiN}_{x}: \mathrm{H}$ 薄膜中的 氢含量时, 在 $3340 \mathrm{~cm}^{-1}$ 处的 $\mathrm{N}-\mathrm{H}$ 键和 $2200 \mathrm{~cm}^{-1}$ 附 近的 $\mathrm{Si}-\mathrm{H}$ 键最重要. ${ }^{13}$ 我们使用 Lanford 和 Rand ${ }^{14}$ 建议的方法, 根据 $\mathrm{Si}-\mathrm{H}$ 键和 $\mathrm{N}-\mathrm{H}$ 键的吸收峰计 算出 $\mathrm{Si}-\mathrm{H}$ 和 $\mathrm{N}-\mathrm{H}$ 键的浓度, 将二者相加就得到 总的氢键浓度. $\mathrm{Si}-\mathrm{N}$ 键的浓度可根据 Bustarret ${ }^{10}$ 和 Giorgis ${ }^{15}$ 等的分析方法计算得到. 表 2 给出了计算得 到的不同沉积温度下制备的 $\mathrm{SiN}_{x}: \mathrm{H}$ 薄膜中 $\mathrm{Si}-\mathrm{N}$ 键、 $\mathrm{Si}-\mathrm{H}$ 键、 $\mathrm{N}-\mathrm{H}$ 键浓度以及 $\mathrm{H}$ 键的总浓度.

从表 2 中可以看到, $\mathrm{SiN}_{x}: \mathrm{H}$ 薄膜中 $\mathrm{Si}-\mathrm{N}$ 键浓度 随着沉积温度升高明显增加, 而 $\mathrm{Si}-\mathrm{H}$ 键和 $\mathrm{N}-\mathrm{H}$ 键浓度则随着沉积温度升高明显减少, $\mathrm{H}$ 键总浓度 自然也明显减少. 这是因为随着沉积温度升高, 在反 应过程中所生成的 $\mathrm{Si}-\mathrm{H}$ 键和 $\mathrm{N}-\mathrm{H}$ 键被破坏, 导 致 $\mathrm{Si}-\mathrm{H}$ 键和 $\mathrm{N}-\mathrm{H}$ 键浓度降低, 由于 $\mathrm{Si}-\mathrm{H}$ 键键能 比 $\mathrm{N}-\mathrm{H}$ 键键能小, 所以随着温度的升高, $\mathrm{Si}-\mathrm{H}$ 键 浓度迅速降低, 而 $\mathrm{N}-\mathrm{H}$ 键浓度减少幅度小得多. $\mathrm{Si}-\mathrm{H}$ 断裂开的 $\mathrm{Si}$ 原子和 $\mathrm{N}-\mathrm{H}$ 键断裂开的 $\mathrm{N}$ 原子 结合生成了一些新的 $\mathrm{Si}-\mathrm{N}$ 键, 使得 $\mathrm{Si}-\mathrm{N}$ 键浓度 升高. 仔细研究发现, 随着温度的升高, $\mathrm{N}-\mathrm{H}$ 键浓 度的降低 $(\mathrm{N}-\mathrm{H}$ 键和 $\mathrm{Si}-\mathrm{H}$ 键浓度降低小的一个) 小于 $\mathrm{Si}-\mathrm{N}$ 键的增加. 这说明 $\mathrm{Si}-\mathrm{N}$ 键浓度随温度 的增加不仅仅来源于 $\mathrm{N}-\mathrm{H}$ 和 $\mathrm{Si}-\mathrm{H}$ 键的断裂重 组, 还来源于前面讨论提到的, 即随着沉积温度升 高, 使吸附到基片表面的活性原子、分子、基团的能 量增加, 粒子在基片表面的扩散、迁移能力增强, 使 得薄膜结构致密. $\mathrm{SiN}_{x}: \mathrm{H}$ 薄膜中 $\mathrm{Si}-\mathrm{N}$ 键的浓度反 映了薄膜的致密度, ${ }^{16}$ 随着薄膜的 $\mathrm{Si}-\mathrm{N}$ 键的浓度增

表 2 不同沉积温度下制备的 $\mathrm{SiN}_{x}: \mathrm{H}$ 薄膜的 $\mathrm{Si}-\mathrm{N}$ 键、

$\mathrm{Si}-\mathrm{H}$ 键、N-H 键以及 $\mathrm{H}$ 键总浓度

Table 2 Bond concentration of $\mathrm{Si}-\mathrm{N}, \mathrm{Si}-\mathrm{H}, \mathrm{N}-\mathrm{H}$, and total $\mathrm{H}(\mathrm{TH})$ bonds of $\mathrm{SiN}_{x}: \mathrm{H}$ film at different deposition temperatures

\begin{tabular}{cccccc}
\hline No. & $T /{ }^{\circ} \mathrm{C}$ & $10^{-23} n_{\mathrm{Si}-\mathrm{N}} / \mathrm{cm}^{-3}$ & $10^{-22} n_{\mathrm{Si}-\mathrm{H}} / \mathrm{cm}^{-3}$ & $10^{-22} n_{\mathrm{N}-\mathrm{H}} / \mathrm{cm}^{-3}$ & $10^{-22} n_{\mathrm{TH}} / \mathrm{cm}^{-3}$ \\
\hline 1 & 400 & 1.03 & 1.69 & 1.13 & 2.82 \\
2 & 425 & 1.06 & 1.27 & 1.00 & 2.27 \\
3 & 450 & 1.17 & 1.21 & 1.02 & 2.23 \\
4 & 475 & 1.24 & 1.11 & 0.98 & 2.09 \\
5 & 500 & 1.29 & 1.11 & 0.97 & 2.08 \\
\hline
\end{tabular}

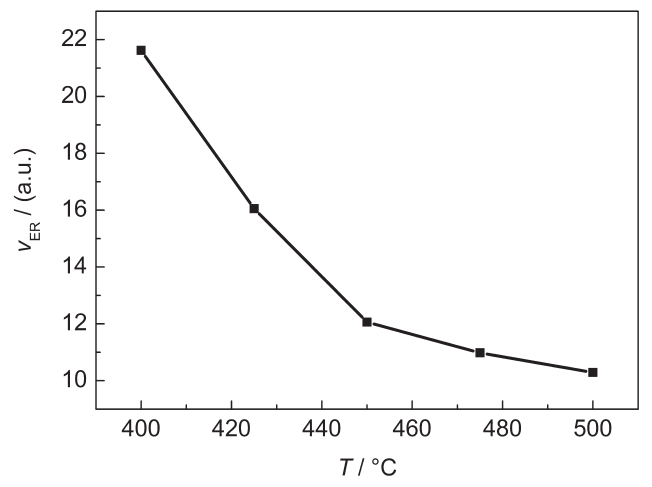

图 2 不同沉积温度的 $\mathrm{SiN}_{x}: \mathrm{H}$ 薄膜在 $\mathrm{HF}$ 溶液中的 腐蚀速率 $\left(v_{\mathrm{ER}}\right)$

Fig.2 Etching rate $\left(v_{\mathrm{ER}}\right)$ of $\mathrm{SiN}_{x}: \mathrm{H}$ film deposited at different temperatures in HF solution

加, 薄膜的质量密度会变大. ${ }^{17}$

图 2 给出了不同沉积温度条件下制备的 $\mathrm{SiN}_{x}: \mathrm{H}$ 薄膜在浓度为 $5 \%(w)$ 的 $\mathrm{HF}$ 溶液中的腐蚀速率 $v_{\mathrm{ER}}$, 随着沉积温度升高, 薄膜的腐蚀速率明显减小. 这正 是因为薄膜的密度增加, 导致 HF 对薄膜的腐蚀速 率降低.

在这些 $\mathrm{SiN}_{\mathrm{x}}$ : $\mathrm{H}$ 薄膜中, $\mathrm{Si}-\mathrm{N}$ 键的浓度均大于 $1 \times 10^{23} \mathrm{~cm}^{-3}$, 这比相关文献给出的 Roth \& Rau公司 用 PECVD 法制备的 $\mathrm{SiN}_{x}: \mathrm{H}$ 薄膜的 $\mathrm{Si}-\mathrm{N}$ 键浓度大 了将近一个数量级, ${ }^{18}$ 说明 Centrotherm 公司用 PECVD 法制备的 $\mathrm{SiN}_{x}: \mathrm{H}$ 薄膜更加致密. Centrotherm 公司的 PECVD 是直接法, Roth \& Rau 公司的 PECVD法是间接法, 间接法等离子体是离子离化后 形成 $\mathrm{SiN}_{x}: \mathrm{H}$, 然后再扩散到硅片表面的, 所以薄膜的 质量较为疏松. $\mathrm{SiN}_{x}: \mathrm{H}$ 薄膜中 $\mathrm{Si}-\mathrm{N}$ 键浓度对薄膜 表面钝化和体针化效果至关重要, ${ }^{19}$ 在 $\mathrm{H}$ 含量相同的 情况下, 对于致密的薄膜, 其钝化特性和减反射特性 都要优越得多.

沉积 $\mathrm{SiN}_{x}: \mathrm{H}$ 薄膜的硅片的有效少子寿命测试 结果如表 3 所示, 表中还给出了有效寿命随着时间

\section{表3 不同沉积温度下制备的 $\mathrm{SiN}_{x}$ : H 薄膜表面钝化的硅片 的有效少子寿命 $\left(\tau_{\mathrm{eff}}\right)$ 和衰减情况}

Table 3 Minority carriers lifetime ( $\tau_{\text {eff }}$ of silicon surface passivation $\mathrm{SiN}_{x}: \mathrm{H}$ film change with different deposition temperatures and time

\begin{tabular}{cccccc}
\hline \multirow{2}{*}{ No. } & \multirow{2}{*}{$T /{ }^{\circ} \mathrm{C}$} & \multicolumn{4}{c}{$\tau_{\mathrm{eff}} / \mu \mathrm{s}$} \\
\cline { 3 - 6 } & & initial & $15 \mathrm{~d}$ & $30 \mathrm{~d}$ & $45 \mathrm{~d}$ \\
\hline 1 & 400 & 20.1 & 13.0 & 10.6 & 11.0 \\
2 & 425 & 30.5 & 17.6 & 15.1 & 15.4 \\
3 & 450 & 37.3 & 23.2 & 19.3 & 19.1 \\
4 & 475 & 31.9 & 20.5 & 17.8 & 17.3 \\
5 & 500 & 33.8 & 19.5 & 16.9 & 16.9 \\
\hline
\end{tabular}


的变化. 表 3 的结果显示, $\mathrm{SiN}_{x}: \mathrm{H}$ 薄膜表面钝化的硅 片的有效少子寿命随着沉积温度的升高先升高后降 低, 在 $450{ }^{\circ} \mathrm{C}$ 处有效少子寿命达到最大值. 沉积温 度过低和过高都会对薄膜的表面钝化效果有不利影 响, 这与薄膜中的固定电荷密度和界面态密度的变 化有关. 硅悬挂键在 $\mathrm{SiN}_{x}: \mathrm{H}$ 薄膜的深能级缺陷中占 主导地位, 又以 $\mathrm{Si}=\mathrm{N}_{3}$ 为主, 称为 $\mathrm{K}$ 心, 在禁带中心 形成高密度的缺陷态. 在氮化硅薄膜中 $\mathrm{K}$ 心存在的 稳定态是 $\mathrm{K}^{+}\left(\mathrm{Si} \equiv \mathrm{N}_{3}^{+}\right)$, 使氮化硅薄膜带正电. ${ }^{20}$ 根据前 面讨论的结果(如表 2 所示), 随着沉积温度的增加, 断裂的 $\mathrm{Si}-\mathrm{H}$ 键要多于断裂的 $\mathrm{N}-\mathrm{H}$ 键, 这说明随 着氢从薄膜中析出, 硅悬挂键增多, 导致固定电荷密 度增加. 因此尽管薄膜中的氢含量降低, 但是由于薄 膜的场钝化效应增强, 从而使硅片的有效少子寿命 变大. 当温度进一步升高后, 随着大量的氢从薄膜中 析出, 在 $\mathrm{SiN}_{x}: \mathrm{H}$ 薄膜与硅界面处的氢含量也开始减 少, 从而导致硅表面大量的悬挂键存在, 增加了界面 态密度, 从而使硅片的有效少子寿命呈现下降趋势. 另外一个现象就是有效少子寿命 $t_{\mathrm{eff}}$ 随着时间有显 著的减小, 经过一个月才趋于稳定, 表面针化效果的 衰减可能与 $\mathrm{Si}_{-}-\mathrm{SiN}_{x}: \mathrm{H}$ 或 $\mathrm{SiN}_{x}: \mathrm{H}$ 薄膜内部特殊的 “弱 键”在紫外光照射下被破坏有关. ${ }^{21}$

\section{3 电池的结果}

表 4 为按照标准的单晶硅太阳电池制作工艺制 备的 5 组电池的电性能测试结果, 每组的数量仍为 10 片左右. 为了保持每组电池对太阳光的外反射一 致, $\mathrm{SiN}_{x}$ : $\mathrm{H}$ 薄膜厚度略有不同(因为不同的沉积温度 折射率不一致). 其余的制作工艺和参数完全一致. 由表 4 可见最高效率点并没有出现在由前面实验结 果得出的最佳有效寿命的制备温度 $450{ }^{\circ} \mathrm{C}$, 而是出 现在 $425^{\circ} \mathrm{C}$.

在采用本文实验中所用的硅片 $(200 \mu \mathrm{m}$ 厚, 1 $\Omega \cdot \mathrm{cm}$ 电阻率)时, 开路电压主要是由基区决定的. 由 于 PECVD沉积薄膜主要影响发射结表面的针化特

表4 电池性能参数

Table 4 Electrical performance of solar cells

\begin{tabular}{cccccccc}
\hline No. & $T /{ }^{\circ} \mathrm{C}$ & Eff. $/ \%$ & $V_{\text {oc }} / \mathrm{mV}$ & $I_{\mathrm{sc}} / \mathrm{A}$ & $R_{\mathrm{s}} / \mathrm{m} \Omega$ & $R_{\mathrm{sh}} / \Omega$ & $\mathrm{FF}$ \\
\hline 1 & 400 & 17.7 & 626 & 5.34 & 6 & 72.6 & 0.785 \\
2 & 425 & 17.8 & 626 & 5.35 & 5.5 & 37 & 0.788 \\
3 & 450 & 17.6 & 626 & 5.33 & 6 & 34.3 & 0.784 \\
4 & 475 & 17.6 & 626 & 5.33 & 5.5 & 14 & 0.785 \\
5 & 500 & 17.5 & 626 & 5.34 & 6 & 10.6 & 0.780 \\
\hline
\end{tabular}

Eff: efficiency; $V_{\mathrm{oc}}$ : open circuit voltage; $I_{\mathrm{sc}}$ : short circuit current intensity; $R_{\mathrm{s}}$ : series resistance; $R_{\mathrm{sh}}$ : shunt resistance; FF: fill factor
性, 所以 5 组电池的开路电压全部相同. 直接能体现 表面钝化特性的短路电流的变化规律与 3.3 节中的 有效少子寿命实验结果相一致, 即随着温度升高先 升高然后降低, 但是最高点出现 $425^{\circ} \mathrm{C}$. 这是因为短 路电流不仅受表面钝化特性的影响而且还受串/并 联电阻的影响. 串联电阻并没有随沉积温度呈现规 律性的变化, 可以认为不受沉积温度的影响; 但是 并联电阻却随着沉积温度的升高而明显单调降低. 并联电阻越低, 短路电流和填充因子越低. 同理, 填 充因子受串/并联电阻和短路电流的影响最高值也 出现在 $425^{\circ} \mathrm{C}$. 这样在本实验的工艺条件下, $425^{\circ} \mathrm{C}$ 的 PECVD沉积温度给出了最优化的效率.

随着沉积温度的升高, $\mathrm{SiN}_{x}$ : $\mathrm{H}$ 薄膜越来越致密; 而薄膜结构越致密导热性就越好, 所以在烧结过程 中, 玻璃银浆更加容易熔化烧穿薄膜. 这样沉积温度 越高, 在相同的烧结工艺下, 并联电阻越低(如表 4 所示). 这也说明在本实验中, 如果能够精细地调节 $450{ }^{\circ} \mathrm{C}$ 沉积的薄膜所对应的烧结工艺, 使并联电阻 足够高, 串联电阻足够低, 将会在 $450{ }^{\circ} \mathrm{C}$ 达到最优 化的电池效率值.

\section{4 结 论}

在 PECVD 法制备 $\mathrm{SiN}_{x}: \mathrm{H}$ 薄膜工艺中, 沉积温 度对薄膜的 $\mathrm{Si} / \mathrm{N}$ 摩尔比、折射率、硅、氮和氢成键结 构以及表面钝化效果有很大影响. 在 $400-500{ }^{\circ} \mathrm{C}$ 的 温度区间制备的 $\mathrm{SiN}_{x}: \mathrm{H}$ 薄膜的折射率分布在 1.926-2.231 之间. 薄膜中的 $\mathrm{Si} / \mathrm{N}$ 摩尔比随着沉积温 度的增加而增加, 导致薄膜的折射率升高. 而 $\mathrm{Si}-\mathrm{H}$ 键和 $\mathrm{N}-\mathrm{H}$ 键浓度随着沉积温度升高会减小, 薄膜 中氢含量降低. 随着沉积温度的增加, $\mathrm{Si}-\mathrm{H}$ 键断裂 形成正电中心提高了场钝化效应, 而 $\mathrm{H}$ 的析出又降 低了体钝化效应, 这两者相互竞争造成了 $\mathrm{SiN}_{x}: \mathrm{H}$ 薄 膜钝化硅片的有效少子寿命先增加后下降. $\mathrm{SiN}_{x}: \mathrm{H}$ 薄膜钝化的硅片还出现明显的时间衰减特性, 对于 造成这种衰减原因还需要进一步的研究. 沉积温度 为 $450{ }^{\circ} \mathrm{C}$ 时制备的 $\mathrm{SiN}_{x}: \mathrm{H}$ 薄膜具有较好的减反射 和表面钝化效果. 采用相同类型的硅片制作的太阳 电池的测试结果也验证了此钝化效果规律. 同时还 发现沉积温度越高, 薄膜越容易被浆料烧穿, 从而并 联电阻越低. 精细地调节烧结工艺将会使 $450{ }^{\circ} \mathrm{C}$ 的 沉积温度给出最优化的效率.

致谢：感谢江苏欧贝黎新能源科技股份有限公司提供部分 
实验设备及屈盛博士、汤叶华硕士给予的有价值的讨论.

\section{References}

(1) Jana, T.; Mukhopadhyay, S.; Ray, S. Sol. Energy Mater. Sol. Cells 2002, 71 (2), 197.

(2) Nijs, J. Advanced Silicon and Semiconducting Silicon-alloy Based Materials and Devices; Taylor \& Francis: Bristol, 1994.

(3) Duerinckx, F.; Szlufcik, J. Sol. Energy Mater. Sol. Cells 2002, 72 (1-4), 231.

(4) Schmidt, J.; Kerr, M. Sol. Energy Mater. Sol. Cells 2001, 65 $(1-4), 585$.

(5) Soppe, W.; Rieffe, H.; Weeber, A. Progress in PhotovoltaicsResearch and Applications 2005, 13 (7), 551.

(6) Santana, G.; Morales-Acevedo, A. Sol. Energy Mater. Sol. Cells 2000, 60 (2), 135.

(7) Lauinger, T.; Moschner, J.; Aberle, A.; Hezel, R. J. Vac. Sci. Technol. A-Vacuum, Surfaces, and Films 1998, 16, 530.

(8) Yoo, J.; Dhungel, S.; Yi, J. Thin Solid Films 2007, 515 (12), 5000 .

(9) Dauwe, S. Low-temperature Surface Passivation of Crystalline Silicon and Its Application to the Rear Side of Solar Cells. Ph. D. Dissertation, Hannover University, Germany, 2004.

(10) Bustarret, E.; Bensouda, M.; Habrard, M.; Bruyere, J.; Poulin, S.; Gujrathi, S. Phys. Rev. B 1988, 38 (12), 8171.

(11) Lelievre, J.; Fourmond, E.; Kaminski, A.; Palais, O.; Ballutaud, D.; Lemiti, M. Sol. Energy Mater. Sol. Cells 2009, 93 (8), 1281.

(12) Tsu, D.; Lucovsky, G.; Mantini, M. Phys. Rev. B 1986, 33 (10), 7069.

(13) Morimoto, A.; Tsujimura, Y.; Kumeda, M.; Shimizu, T. Jpn. J. Appl. Phys 1985, 24 (11), 1394.
(14) Lanford, W.; Rand, M. J. Appl. Phys 1978, 49, 2473.

(15) Giorgis, F.; Giuliani, F.; Pirri, C.; Tresso, E.; Summonte, C.; Rizzoli, R.; Galloni, R.; Desalvo, A.; Rava, P. Philosophical Magazine Part B 1998, 77 (4), 925.

(16) Hong, J.; Kessels, W.; Soppe, W.; Rieffe, H.; Weeber, A.; van de Sanden, M. Structural Film Characteristics Related to the Passivation Properties of High-rate ( $>0.5 \mathrm{~nm} / \mathrm{s}$ ) Plasma Deposited a-SiN $x: H$. In 3rd World Conf. on Photovoltaic Energy Conversion; Osaka, 2003; Wcpec-3 Organizing Committee: TYokyo, Japan, 2003; 1185.

(17) Soppe, W.; Hong, J.; Kessels, W.; van de Sanden, M.; Arnoldbik, W.; Schlemm, H.; Devilée1, C.; Rieffe1, H.; Schiermeier1, S.; Bultman, J.; Weeber1, A. On Combining Surface and Bulk Passivation of $\mathrm{SiN}_{x}: \mathrm{H}$ Layers for mc-Si Solar Cells. In Proc. 29th IEEE Photovoltuic Specialists Conference, New Orleans, 2002; IEEE: New York, USA, 2002; $158-161$.

(18) Cuevas, A.; Chen, F.; Tan, J.; Mackel, H.; Winderbaum, S.; Roth, K. FTIR Analysis of Microwave-Excited PECVD Silicon Nitride Layers. In 4th World Conference on Photovoltaic Energy Conversion, Waikoloa, Hawaii, 2006; IEEE: New York, USA, 2006; 1148-1151.

(19) Weeber, A.; Rieffe, H.; Romijn, I.; Sinke, W.; Soppe, W. The Fundamental Properties of $\mathrm{SiN}_{x}: \mathrm{H}$ That Determine Its Passivating Qualities. In 31st IEEE PVSC Conf, Florida, 2005; IEEE: New York, USA, 2005; 1043-1046.

(20) Robertson, J.; Warren, W.; Kanicki, J. J. Non-Cryst. Solids 1995, $187,297$.

(21) Hezel, R.; Jaeger, K. J. Electrochem. Soc 1989, 136 (2), 518. 